\title{
Algae Bioactive Constituents and Possible Role During COVID-19 Pandemic (A review)
}

Sayed Rashad*,1 and Ghadir A. El-Chaghaby**

*Regional Center for Food and Feed, Agricultural Research Center, Giza, Egypt.

\begin{abstract}
Nowadays, the use of natural bio-products in pharmaceuticals is gaining popularity as safe alternatives to chemicals and synthetic drugs. Algal products are offering a pure, healthy and sustainable choice for pharmaceutical applications. Algae are photosynthetic microorganisms that can survive in different environmental conditions. Algae have many outstanding properties that make them excellent candidate for use in therapeutics. Algae grow in fresh and marine waters and produce in their cells a wide range of biologically active chemical compounds. These bioactive compounds are offering a great source of highly economic bio-products. The present review discusses the phytochemical and bioactive compounds present in algae biomass and their potent biological activities. The review focuses on the use of alga in therapy and their pharmaceutical applications with special reference to the possible preventive and therapeutic role of algae against COVID-19.
\end{abstract}

Keywords: Algae, Bioactivity, Therapeutic role, Bio-products, COVID-19, Pharmaceutical

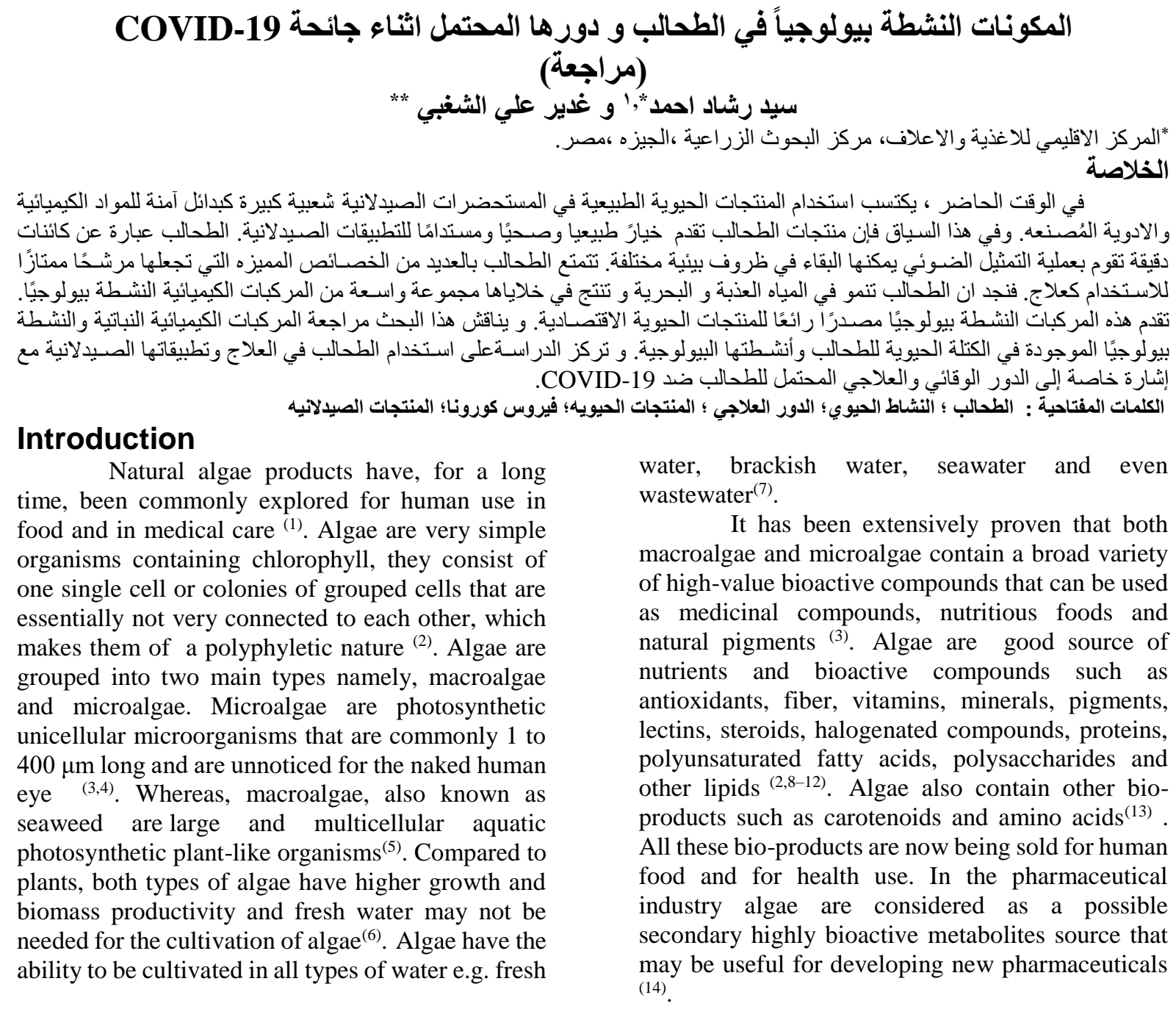

${ }^{1}$ Corresponding author E-mail: sayed_rashad79@hotmail.com

Received:23 /1/2021

Accepted:1/3/2021

Published Online First: 2021-12-09

Iraqi Journal of Pharmaceutical Science 
Several experimental studies were carried out on the bioactive chemical compounds derived for human gain and welfare from algal biomass. In the present review, a summarized overview of the phytochemical and bioactive compounds present in algae biomass and their potent biological activities is presented. Also, the review points out the pharmaceutical, economic and future prospects for algae role during the present COVID-19 pandemic.

Algae

Algae represent a diverse group of largely photosynthetic aquatic organisms ${ }^{(9,15)}$. Algae can be unicellular, colonial or filamentous, leading to a wide diversity in overall cell morphology ${ }^{(16)}$. They are present both in aquatic and in fresh water and have a short duplication period, making them one of the most quickly developing species ${ }^{(17)}$. Algae have diverse methods of assessing and effectively using ambient carbon dioxide and nutrients for biomass production ${ }^{(8,18)}$. The cell walls of algae are thin, rigid but variable in their conformation and they surround the plasma membranes ${ }^{(16)}$.

In a water body, algal development is a dynamic process characterized by a wide variety of chemical, physical and biological progressions in the interior and it is influenced by a range of environmental factors in the outside. The key factors affecting algal growth have been established as total nitrogen, phosphorus, water temperature, and light strength, and their synergistic effects contribute to algae growth ${ }^{(19)}$.

Algae constitute a group of photosynthetic eukaryotic species $^{(20)}$ that are either autotrophic which use water, light, carbon dioxide and other nutrients to produce their own food or polyphyletic which are large and diverse. Algae on the basis of their morphological characteristics comprise microalgae made up of only one cell or macroalgae (seaweed) that use many different cells to function (21) and they can be identified in freshwater, marine habitats and also on wet rocks ${ }^{(22) .}$

\section{Microalgae}

Microalgae are part of the subgroup of algae comprising thousands of types and are in essence photosynthetic. They are categorized as cyanobacteria, rhodophytes, chlorophytes and chromophytes $^{(23)}$. Microalgae comprises photosynthetic microorganisms that are prokaryotic or eukaryotic, they are single or multicellular in structure $^{(24)}$.

In freshwater and marine environments, microalgae constitute one of the most diverse classes of microorganisms ${ }^{(25)}$. In taxonomy, microalgae denote eukaryotic microorganisms. However, microalgae include in their widest description prokaryotic cyanobacteria, green algae, diatoms, etc. ${ }^{(26)}$

The green algae, which belong to phylum chlorophyta and contain common generations such as chlorella, dunaliella, and haematococcus are a particularly significant group of microalgae. Another large group is the phylum Heterokontophyta diatoms and includes common genera such as Phaeodactylum ${ }^{(22,27-29)}$.

Microalgae represent a source of immense bioactive compounds such as antiviral, antibacterial, antifungal and anticancer ${ }^{(30)}$ that can be used for commercial applications. Various microalgae pharmaceutical products have high potential, but their commercialization is still in its initial stages and can be perceived as a portal to the industry worth some billion dollars in the near future (31). The genetic potential of microalgae for different bioactive agents is amazing. These microorganisms, as in the pharmaceutical industry, have been shown to be able to manufacture certain compounds in the biotechnological spotlights for use and marketing ${ }^{(32,33)}$.

\section{Macroalgae}

Macroalgae, as a fresh and renewable compound source, are currently being researched for both pharmaceutical and nutraceutical applications $^{(25)}$. They can be categorized according to the presence of distinctive pigments into green algae (Chlorophyceae), brown algae (Phaeophyceae) and red algae (Rhodophyceaeae) $(34,35)$. According to ${ }^{(36)}$ there are 11017 species of macroalgae on earth and they are distributed as 1901 , 7083 and 2033 for green ,red and brown algae, respectively.

Marine macroalgae have been a significant source of biological and natural compounds including antidiabetic, vitamins, antibacterial and antiviral agents. Macroalgae are renowned for their excellent health, ecological health with a high content of minerals and nutritious fibres ${ }^{(37)}$.

\section{Bioactive constituents of algae}

Algae are rich resources for many compounds that are bioactive, including primary and secondary metabolites and that could be used in the pharmaceutical sector as possible candidates of interest ${ }^{(28)}$. Algae have been proved to be vitamins and vitamin precursors source including ascorbic acid, riboflavin and tocopherol ${ }^{(38)}$. Algae include a wide variety of medicinal drugs, vaccines, nutritive elements, proteins, which are not otherwise available or which are very expensive to obtain from plant and animal sources ${ }^{(33,39)}$

\section{Antioxidants}

Inflammations and oxidative stress especially in the presence of chronic diseases linked to antioxidant system fragility, are key factors that increase the severity of COVID-19. These data endorse the advice for the supplementation of antioxidants as effective COVID-19 strategies ${ }^{(40)}$.

Antioxidants perform an essential role in the regeneration of damaged cells ${ }^{(41)}$. In order to avoid these diseases and health issues, antioxidants 
terminate the attacks of reactive oxygen species and dramatically controlled oxidative reactions and thus antioxidants are of utmost importance (42). Antioxidants have a critical role in the prohibition of many disease such as cancer, autoimmune disorders, neurological degeneration and coronary heart. Nowadays, many experts are interested in finding healthy and satisfactory natural antioxidants.

Algae were shown to resist oxidative damages and persist despite exposure to reactive oxygen species and this indicates that algae cells have protective antioxidant defense systems ${ }^{(43)}$.

Natural antioxidants present in many algae are essential bioactive compounds, which play a key role in protecting cells against oxidative damage in various diseases and aging processes. ${ }^{(43)}$.

Sevral algae species showed potential antioxidant activity. Zouaoui and co-authors ${ }^{(44)}$ categorized the algal antioxidants into two groups; (1) water-soluble and (2) fat- soluble. Some of the studies reporting the antioxidant properties of algae species are summarized below.

Anti-oxidant ability has been reported to be correlated with filamentous, green marine algae of Chaetomorf species including C. aerea, C. crassa, C. linum and C. brachygona. In contrast with other plant species C. linum displayed the highest antioxidant potential with a relatively low minimum inhibitory concentration $\mathrm{IC}_{50}(1.484 \pm 0,168 \mathrm{mg} \mathrm{mL}$ $\left.{ }^{1}\right)$, a highest flavonoid content $(18.177 \pm 2.238 \mathrm{mg}$ /g as Rutin equivalent) and a relatively low phenolic content $(2,895 \pm 0,415 \mathrm{mg} / \mathrm{g}$ as gallic acid equivalent) ${ }^{(45)}$.

The six brown algae, Sargassum linearifolium, Sargassum vestitum, Hormosira banksia, Phyllospora comosa, Padina sp., and Sargassum podocanthum were reported to have antioxidant activity that was correlated to their phenolic compounds content and the six algae were found to contain the potent antioxidant compound "fucoxanthin"(46).

In the four edaphic algae Vaucheria geminate, Pleurochloris pyrenoidosa, Botrydiopsis eriensis, and Scenedesmus obliquus, seven phenol compounds were identified (resorcinol, gallic acid, chlorogenic acid, syringic acid, caffeic acid, coumaric acid and ferulic acid). The four species showed high total antioxidant capacity that ranged from 6.66 to 36.33 ( $\mathrm{mg}$ of Ascorbic acid/g) and also they showed up to $97.37 \%$ inhibition for Dimethyl phenyl hydrazyl (DPPH) free radical ${ }^{(28)}$.

The main algal species used to manufacture astaxanthin belongs to the genus Haematococcus, but it is also produced by some Chlorella species, such as Chlamydomonas nivalis. Astaxanthin is highly important due to its high antioxidant ability and associated health benefits ${ }^{(47)}$.

For its antioxidant qualities, ethanolic and aqueous extracts from seaweed Polysiphonia and Laurencia have been compared. The content of flavonoids, phenol, and tannins was higher in Polysiphonia. Also, Polysiphonia displayed higher levels of antioxidant activity relative to Laurencia for both ethanol and water extracts ${ }^{(48)}$.

Methanol extracts of the red seaweed, Chondrococcus hornemannii and Spyridia fusiformis were reported to have high antioxidant activity owing to their phytochemical composition including flavonoids, tannin, alkaloids, saponin and steroids ${ }^{(49)}$.

The methanol extract of blue green algae, Anabaena sp. exhibited high antioxidant activity with phenolic content equal to 57.06 gallic acid equivalent (mg/gm) and DPPH radical scavenging activity $48.62 \pm 0.29 \%$ at $100 \mathrm{mg} / \mathrm{ml}$ concentration with an $\mathrm{IC}_{50}$ value of 101.81 $\mathrm{mg} / \mathrm{ml}^{(50)}$.

\section{Antivirals}

Viral infections are a big public health concern causing multiple illnesses that endanger health. Many investigations seek to detect novel antivirals in order to monitor and disseminate these contagious conditions ${ }^{(51)}$. Synthetic antiviral drugs were developed to diminish the virus infections 'complications. On the other hand, serious side effects and development of some resistant mutants of the virus were documented, particularly for longterm antiviral medication ${ }^{(52)}$.

In many studies, researches were driven towards investigating natural sources of antiviral drugs. The antiviral properties of macroalgae have a defensive function against many species of viruses $^{(53,54)}$. The antiviral activity against certain retroviruses have been found to be compatible with bioactive compounds isolated from microalgae. Steroids and algae-extracted glycolipids have HIV bioactivity ${ }^{(55)}$. Algae bioactive constituents especially algae derived-polysaccharides have been demonstrated to have potential antiviral activity that could be effective in the treatment of viral infections. In the present review, we are summarizing some of the studies that highlight algae role as antiviral agent ${ }^{(56)}$.

Methanol extract of Spirulina platensis isolated from the Nile River in Egypt recorded a pronounced antiviral activity with $50 \%$ reduction of viral titer. The observed antiviral activity of Spirulina was attributed to its content of sulphoquinovosyl diacylglycerol ${ }^{(57)}$. Sulphoquinovosyl diacylglycerol is a natural sulpholipid extensive biological activities such as inhibitory effects on DNA polymerase and HIVreverse transcriptase, $\mathrm{P}$-selectin receptors, the AIDS virus, telomerase, and inflammation/proliferation (58).

The red microalga Porphyridium cell-wall sulphated polysaccharide showed remarkable antiherpes simplex virus type (HSV 1,2), and Herpes zoster virus type 1 and 2 (HSV 1, 2) Variicella sp $(\mathrm{VZV})^{(59)}$. 
Sulfolipids with remarkable antiviral activity against herps simplex virus type1 (HSV-1) were isolated from different marine algal species (Laurencia popillose, Galaxoura cylindriea, Ulva fasciata, Dilophys fasciola and Taonia atomaria) ${ }^{(60)}$.

The algal extracts of Spirogyra showed anti-HSV activity in different phases of the multiplication processes of herpes simplex virus type 1 (HSV 1) and type 2 virus (HSV-2). Alkaloids, essential oils and terpenoids were the major active compounds against HSV found in Spirogyra spp ethanolic extract ${ }^{(61)}$.

Aqueous extract from the red macroalga Laurencia obtusa inhibited the replication of the viruses: influenza B, A (H3N2) and A (H1N1) ${ }^{(62)}$.

Marine species of Seaweed Osmundaria obtusiloba extract revealed high levels Chikungunya virus (CHIKV) infection ${ }^{(63)}$.

The anti-HIV-1 activity of the bioactive compound Fucoidan extracted from two different marine macroalgae

bartayesiana and Turbinaria decurrens was proved $^{(63)}$.

Murine leuchemia virus (MuLV), and cell transformation by murine-sarcoma virus (MuSV124) in cell culture have been substantially inhibited by polysaccharides isolated from the red microalgae Porphyridium sp. ${ }^{(64)}$.

Lectins were extracted and purified from Canavalia brasiliensis , C.maritima ,Dioclea. lasiocarpa, D. sclerocarpa ,Amansia multifida , Bryothamniom seaforthii, Hypnea musciformis, Meristiella echinocarpa and Solieria filiformis. The isolated lectins were efficient for inhibiting 18 different viruses, including HIV and influenza viruses ${ }^{(65)}$.

Antiviral activity against the type 1 Herpes simplex virus, HSV-1 virus and the Rift valley fever virus (RVFV) were investigated and proved for the carragene sulfated polysaccharides isolated from red alga Acanthophora and brown alga Clathratus Hydroclathrus ${ }^{(66)}$.

\section{COVID-19 disease progression}

The emergence of coronavirus (COVID19) began last November in Wuhan, China, exhibiting pneumonia-like symptoms in patients. By the end of January 2020, the World Health Organization (WHO) declared COVID-19 as a pandemic ${ }^{(67)}$.

Coronaviruses are enveloped viruses that have a single-stranded, positive-sense RNA genome on their surface carrying spike protein. SARS-CoV2 has high transmissibility and has contributed to a public health epidemic worldwide. Symptoms of COVID-19 range from mild flu-like illness to a potentially fatal syndrome of acute respiratory failure or fulminant pneumonia. Since 2012, more than 800,000 individuals have died as a result of
SARS CoV-1 and MERS CoV. In March 2020, the pandemic was declared a pandemic ${ }^{(68)}$

COVID-19 has an unceasingly rising mortality rate of $0.5-1$ percent. An easy way to resist viral infection and reduce fatalities has been to improve immunity. There are currently no drugs and/or vaccines that can help mitigate this viral disease, but spread can be limited by the use of masks and social distancing ${ }^{(69)}$. The healthcare systems of the entire world are struggling to solve this pandemic. Millions of lives have been disrupted because of mandatory isolation or quarantines ${ }^{(70)}$.

\section{Algae prospective during COVID-19 pandemic}

During the current COVID-19 pandemic, scientist all over the world are seeking for exploring new drugs to prevent the infection and to treat the illness but this may take time to verify. In this respect, algae bioactive compounds having antioxidant and antiviral activities could be explored as possible supportive therapy.

Some of the recently tested algal compounds have been promising indications that they are both pharmacologically and commercially efficient antiviral agents and can be used worldwide on a commercial basis to eliminate the infectious pathogen responsible for the COVID-19 pandemic worldwide ${ }^{(71)}$.

According to Pereira and Critchley (72) marine algae species possess large amounts of sulphate polysaccharides of complex structures, which have been shown to inhibit the replication of viruses. The probable antiviral therapeutic antiviral agents against SARS-CoV-2 include molecules such as lectin, carrageen, sulphated polysaccharides, ulvans and fucoidans.

The capacity of algae-based nutraceuticals, in particular spirulina, to improve immunity to viral diseases has already been clinically documented. Spirulina is considered as a potential bioresource of inhibitory therapeutic-value peptides that may be investigated in the treatment and inflammation of extreme symptoms associated with betacoronavirus, like COVID-19 ${ }^{(69)}$.

\section{Conclusion}

Presently, most of the researchers are seeking for the development of successful prevention and treatment therapies to prevent infection and cure of COVID-19. Natural bioactive compounds could offer an excellent solution in getting a handle on this pandemic. In this review, we summarized some important studies that discussed the antioxidant, and antiviral properties of Algaebased nutraceuticals and bioactive compounds. In those studies, algae bioactive ingredients were proven to serve as immune-boosting and therapeutic agents. The present review shed the light about the use and pharmaceutical applications of algae in therapy, with particular reference to the possible 
preventive and therapeutic functions of algae bioactive compounds against COVID-19.

\section{References}

1. Pooja S. Algae used as Medicine and Food-A Short Review. J Appl Pharm Sci Res. 2014;6(162):33-5.

2. Aditya T, Bitu G, G ME. The Role of Algae in Pharmaceutical Development. Spec Issue Rev Pharm Nanotechnol Res Rev J Pharm Nanotechnol. 2016;4:82-9.

3. Nethravathy MU, Mehar JG and Mudliar SN, et al. Recent Advances in Microalgal Bioactives for Food, Feed, and Healthcare Products: Commercial Potential, Market Space, and Sustainability. Compr Rev Food Sci Food Saf. 2019;18(6):1882-97.

4. Rashad S, El-Chaghaby GA, Elchaghaby MA. Antibacterial activity of silver nanoparticles biosynthesized using spirulina platensis microalgae extract against oral pathogens. Egypt J Aquat Biol Fish. 2019;23(5 Special Issue): 261-266.

5. Khan MI, Shin JH, Kim JD. The promising future of microalgae: Current status, challenges, and optimization of a sustainable and renewable industry for biofuels, feed, and other products Microb Cell Fact. 2018;17(36). https://doi.org/10.1186/s12934-018-0879-x

6. Ding L, Chan Gutierrez E and Cheng J, et al. Assessment of continuous fermentative hydrogen and methane co-production using macro- and micro-algae with increasing organic loading rate. Energy. 2018;151:760-70.

7. Morales M, Collet $\mathrm{P}$ and Lardon L, et al. Lifecycle assessment of microalgal-based biofuel. In: Biofuels from Algae. Elsevier; 2019. p. 50750.

8. Gayathri R, Mahboob S and Govindarajan M, et al. A review on biological carbon sequestration: A sustainable solution for a cleaner air environment, less pollution and lower health risks. J King Saud Univ - Sci. 2021;33(2):101282.

9. Brodie J, Chan CX and De Clerck O, et al. The Algal Revolution. Trends Plant Sci. 2017;22(8):726-38.

10. Wells ML, Potin P and Craigie JS, et al. Algae as nutritional and functional food sources: revisiting our understanding J Appl Phycol . 2017; 29, 949-982.

11. Angell AR, Mata L and de Nys R, et al. The protein content of seaweeds: a universal nitrogen-to-protein conversion factor of five. J Appl Phycol. 2016 Feb 1;28(1):511-24.

12. Mostafa SS, El-Hassanin AS and Soliman AS, et al. Microalgae growth in effluents from olive oil industry for biomass production and decreasing phenolics content of wastewater. Egypt J Aquat Biol Fish. 2019;23(1): 359-365.

13. Mishra N, Gupta $E$ and Singh $P$, et al. Application of microalgae metabolites in food and pharmaceutical industry. In: Preparation of Phytopharmaceuticals for the Management of Disorders. Elsevier; 2021:391-408.

14. de Jesus Raposo MF, de Morais RMSC, de Morais AMMB. Health applications of bioactive compounds from marine microalgae. Life Sci. 2013;93(15):479-86.

15. Ynalvez RA, Dinamarca J, Moroney J V. Algal Photosynthesis. 2018; John Wiley \& Sons, Ltd. Available from: http :// doi .wiley .com /10 .1002 /9780470015902.a0000322.pub3

16. Pepper IL, Gentry TJ. Microorganisms Found in the Environment. In: Environmental Microbiology: Third Edition. Elsevier Inc.; 2015. p. 9-36.

17. Sharma P, Sharma N. Industrial and Biotechnological Applications of Algae: A Review. J Adv Plant Biol. 2017; 1(1):1-25.

18. Fayiga AO, Ipinmoroti MO, Chirenje $T$. Environmental pollution in Africa. Vol. 20, Environment, Development and Sustainability. Springer Netherlands; 2018. 41-73 p.

19. Wang C, Wang Z, Wang P, Zhang S. Multiple Effects of Environmental Factors on Algal Growth and Nutrient Thresholds for Harmful Algal Blooms: Application of Response Surface Methodology. Environ Model Assess. 2016 ;21(2):247-59.

20. Raven JA, Giordano M. Algae. Vol. 24, Current Biology. Cell Press; 2014. p. R590-5.

21. Biris-Dorhoi ES, Michiu D and Pop CR, et al. Macroalgae - A sustainable source of chemical compounds with biological activities. Nutrients. 2020;12(10):1-23.

22. Kalacska M, Lucanus $O$ and Sousa L et al. Freshwater fish habitat complexity mapping using above and underwater structure-frommotion photogrammetry. Remote Sens. 2018;10(12):1-28.

23. Singh $\mathrm{S}$, Kate $\mathrm{BN}$, Banecjee UC. Bioactive compounds from cyanobacteria and microalgae: An overview. Crit Rev Biotechnol. 2005 ;25: 73-95.

24. Sharma P, Slathia PS, Raina N, Bhagat D. Microbial diversity in freshwater ecosystems and its industrial potential. In: Freshwater Microbiology: Perspectives of Bacterial Dynamics in Lake Ecosystems. Elsevier; 2019. p. 341-92.

25. Barkia I, Saari N, Manning SR. Microalgae for high-value products towards human health and nutrition. Marine Drugs. 2019;17(5): 304.

26. Amin SA, Parker MS, Armbrust E V. Interactions between Diatoms and Bacteria. Microbiol Mol Biol Rev. 2012;76(3):667-84. 
27. Hallmann A. Algae Biotechnology - Green Cell-Factories on the Rise. Curr Biotechnol. 2015;4(4):389-415.

28. $\mathrm{Fu} \mathrm{W}$, Nelson $\mathrm{DR}$ and $\mathrm{Yi} \mathrm{Z}, \mathrm{Xu} \mathrm{M}$, et al. Bioactive Compounds From Microalgae: Current Development and Prospects. Stud Nat Prod Chem. 2017;54:199-225.

29. Bains JS, Shaw CA. Neurodegenerative disorders in humans: The role of glutathione in oxidative stress-mediated neuronal death. Brain Res Rev. 1997;25(3):335-358.

30. Rashad S, El-Hassanin AS, and Mostafa SSM, et al. Cyanobacteria cultivation using olive milling wastewater for bio-fertilization of celery plant. Glob J Environ Sci Manag. 2019;5(2):167-74.

31. Priyadarshani B, Rath I. Bioactive compounds from microalgae and cyanobacteria: utility and applications Int J Pharm Sci Res. 2012;3(11): 4123-30.

32. De Morais MG, Vaz BDS and De Morais EG, et al. Biologically Active Metabolites Synthesized by Microalgae. Biomed Research International. 2015:835761.

33. Sharma N, Sharma $P$. Industrial and Biotechnological Applications of Algae: A Review. J Advance Plant Biol. 2017;1 (1): 125.

34. Rashad S, El-Chaghaby GA. Marine Algae in Egypt: distribution, phytochemical composition and biological uses as bioactive resources (a review). Egy J Aqua Biol Fish. 2020; 24(5): 147 $-160$.

35. Barbosa M, Valentão $P$, Andrade PB. Bioactive compounds from macroalgae in the new millennium: Implications for neurodegenerative diseases. Mar Drugs. 2014;12(9):4934-72.

36. Stiger-Pouvreau V, Zubia M. Macroalgal diversity for sustainable biotechnological development in French tropical overseas territories. Bot Mar. 2020;63(1):17-41.

37. Zhao C, Yang C and Liu B, et al. Bioactive compounds from marine macroalgae and their hypoglycemic benefits. Trends Food Sci Technol. 2018;72:1-12.

38. Del Mondo A, Smerilli A, Sané E, Sansone C, Brunet C. Challenging microalgal vitamins for human health. Microb Cell Fact. 2020;19(1):123.

39. El-Chaghaby GA, Rashad S and Abdel-Kader SF, et al. Assessment of phytochemical components, proximate composition and antioxidant properties of Scenedesmus obliquus, Chlorella vulgaris and Spirulina platensis algae extracts. Egy J Aqua Biol Fish. 2019; 23(4): $521-526$.

40. Lammi C, Arnoldi A. Food-derived antioxidants and COVID-19. J Food Biochem. 2020;00:e13557

41. Oskouei Z, Akaberi M, Hosseinzadeh H. A glance at black cumin (Nigella sativa) and its active constituent, thymoquinone, in ischemia: A review. Iran $J$ Basic Med Sci. 2018;21(12):1200-9.

42. Ebrahimzadeh MA, Nabavi SM and Nabavi SF, et al. Antioxidant and Antihaemolytic Activities of the Leaves of Kefe cumin ( Laser trilobum L ) Umbelliferae. 2010;9(July):441-9.

43. Kelman D, Posner EK and McDermid KJ, et al. Antioxidant activity of Hawaiian marine algae. Mar Drugs. 2012;10(2):403-16.

44. Zouaoui B, Bachir R and Sahnouni F, et al. Anioxidant Activities of Sulfated Polysaccharide obtained from red algae Corallina officinalis. Int J Pharmacog. 2017; 4(3): 88-91.

45. Farasat M, Khavari-Nejad RA and Nabavi $\mathrm{SMB}$, et al. Antioxidant properties of some filamentous green algae (Chaetomorpha Genus). Brazilian Arch Biol Technol. 2013;56(6):921-7.

46. Dang TT, Bowyer MC and Van Altena IA, et al. Comparison of chemical profile and antioxidant properties of the brown algae. Int J Food Sci Technol.;53(1):174-81.

47. Ip P-F, Chen F. Production of astaxanthin by the green microalga Chlorella zofingiensis in the dark. Process Biochem. 2005;40(2):733-8.

48. Al-Amro AA, Al-Mutlaq MA and Al-Moauthe $S$ et al. Antioxidant Activity of Rhodophyta Algae Polysiphonia and Laurencia Collected from the Arabian Gulf. Asian J Appl Sci.2019;12(2):71-5.

49. Hermawan J, Masithah ED, Tjahjaningsih W. Antioxidant activity of three microalgae Dunaliella salina, Tetraselmis chuii and Isochrysis galbana clone Tahiti IOP Conf Ser Earth Environ Sci. 2017;55:12067.

50. Pant G, Kumar $G$ and Karthik L, et al. Antioxidant activity of methanolic extract of blue green algae Anabaena sp. (Nostocaceae) Europ J Exp Biol. 2011; 1( 1):156-162.

51. Bedoux G, Caamal-Fuentes $E$ and Boulho R, et al. Antiviral and cytotoxic activities of polysaccharides extracted from four tropical seaweed species. Nat Prod Commun. 2017;12(6):807-11.

52. Zandi K, Salimi M, Sartavi K. In vitro antiviral activity of the red marine alga from Persian Gulf, Gracilaria salicornia, against herpes simplex virus type 2. J Biol Sci. 2007;7(7):1274-7.

53. Hamed SM, Abd El-Rhman AA and AbdelRaouf et al. Role of marine macroalgae in plant protection \& improvement for sustainable agriculture technology. Beni-Suef Univ J Basic Appl Sci. 2018;7(1):104-10. 
54. Klongklaew $\mathrm{N}$, Praiboon $\mathrm{J}$ and Tamtin $\mathrm{M}$, et al. Antibacterial and antiviral activities of local Thai green macroalgae crude extracts in pacific white shrimp (litopenaeus vannamei). Mar Drugs. 2020;18(3):1-23.

55. Rahman A, editor. Studies in Natural Products Chemistry: Bioactive Natural Products [Internet]. 1st Edition Elsevier; 2021.

56. Ahmadi A, Zorofchian Moghadamtousi $S$ and Abubakar S, et al. Antiviral potential of algae polysaccharides isolated from marine sources: A review. Biomed Res Int. 2015;2015.

57. Abdo SM, Hetta MH and El-Senousy WM, et al. Antiviral activity of freshwater algae. J Appl Pharm Sci. 2012;2(2):21-5.

58. Chirasuwan $N$, Chaiklahan $R$ and Kittakoop $P$, et al. Anti HSV-1 activity of sulphoquinovosyl diacylglycerol isolated from Spirulina platensis. Science Asia. 2008;35: 137-141.

59. Huleihel M, Ishanu $\mathrm{V}$ and $\mathrm{Tal} J$, et al. Antiviral effect of red microalgal polysaccharides on Herpes simplex and Varicella zoster viruses. J Appl Phycol.2001;13(2):127-34.

60. Baz FK El, Baroty GS El and Baky HHA El, et al. View of Structural characterization and Biological Activity of Sulfolipids from selected Marine Algae. Grasas y aceites 2013;64(5):561-71.

61. Deethae A, Peerapornpisal Y and Pekkoh J, et al. Inhibitory effect of Spirogyra spp. algal extracts against herpes simplex virus type 1 and 2 infection. J Appl Microbiol. 018;124(6):1441-53.

62. Pérez-Riverol A, Alexander Piñón Ramos I and Luis Francisco et al., Antiviral activity of an aqueous extract from the red alga Laurencia obtusa against influenza $\mathrm{A}$ and $\mathrm{B}$ viruses. Revista Cubana de Medicina Tropical. 2014; 66 (2):1-6.

63. Cirne-Santos $\mathrm{CC}$, Barros $\mathrm{C}$ de $\mathrm{S}$ and Nogueira $\mathrm{CCR}$, et al. Inhibition by Marine Algae of Chikungunya Virus Isolated From Patients in a
Recent Disease Outbreak in Rio de Janeiro. Front Microbiol. $2019 ; 10($ OCT):2426.

64. Talyshinsky MM, Souprun YY, Huleihel MM. Anti-viral activity of red microalgal polysaccharides against retroviruses. Cancer Cell Int. 2002;2(1):8.

65. Gondim ACS, Roberta Da Silva S and Mathys L, et al. Potent antiviral activity of carbohydrate-specific algal and leguminous lectins from the Brazilian biodiversity. Medchemcomm. 2019;10(3):390-8.

66. Gomaa HHA, Elshoubaky GA. Antiviral Activity of Sulfated Polysaccharides Carrageenan from Some Marine Seaweeds Journal of Curr Pharm Rev Res. 2015 Available from: www.ijcpr.com

67. Nguemdjo U, Meno F and Dongfack A, et al. Simulating the progression of the COVID-19 disease in Cameroon using SIR models. PLoS One. 2020;15(8):1-10.

68. García-Silva SR-MI, González-Ortega $\mathrm{O}$ and Malla JMS-VA, et al. The Potential of Algal Biotechnology to Produce Antiviral Compounds and Biopharmaceuticals. Molecules. 2020;25(3):1-25.

69. Ratha SK, Renuka $\mathrm{N}$ and Rawat I, et al. Prospectives of algae derived nutraceuticals as supplements for combating COVID-19 and human coronavirus diseases. Nutrition. 2020;111089.

70. Musale AS, Kumar GRK and Sapre A, et al. Marine Algae as a Natural Source for Antiviral Compounds. AIJR. 2020;38(1):1-6.

71. Sangtani R, Ghosh A and Jha HC, et al. Potential of algal metabolites for the development of broad-spectrum antiviral therapeutics: Possible implications in COVID19 therapy. Phyther Res. 2020;ptr.6948.

72. Pereira L, Critchley AT. The COVID 19 novel coronavirus pandemic 2020: seaweeds to the rescue? J Appl Phycol. 2020;2009-11.

Baghdad Iraqi Journal Pharmaceutical Sciences by bijps is licensed under a Creative Commons Attribution $\underline{4.0}$ International License. Copyrights@ 2015 College of Pharmacy - University of Baghdad. 